ORIGINAL ARTICLE

\title{
Pediatric Residents' and Medical Interns' Awareness about Pediatric Ionizing Radiation Dose from Computed Tomography and Its Associated Risks in Tertiary Hospital in Ethiopia
}

\author{
Seife Teferi ${ }^{1 *}$, Daniel Zewdeneh ${ }^{1}$, Solomon Bekele $^{1}$
}

\section{OPEN ACCESS}

Citation: Seife Teferi, Daniel Zewdeneh, Solomon Bekele. Pediatric Residents' and Medical Interns' Awareness about Pediatric Ionizing Radiation Dose from Computed Tomography and Its Associated Risks at Tikur Anbessa Specialized Referral and Teaching Hospital. Ethiop J Health Sci. 2017; 28(4):383.

doi:http://dx.doi.org/10.4314/ejhs.v28i4.4

Received: December 25, 2017

Accepted: December 27, 2017

Published: July 1, 2018

Copyright: (C) 2018 Seife teferi, et al

This is an open access article distributed under the terms of the Creative Commons

Attribution License, which permits unrestricted use, distribution, and reproduction in any medium, provided the original author and source are credited.

Funding: Nil

Competing Interests: The authors declare that this manuscript was approved by all authors in its form and that no competing interest exists.

Affiliation and Correspondence:

${ }^{1}$ Department of Radiology, College of

Health Sciences, Addis Ababa

University

*Email: seifeteferi@yahoo.com

\section{ABSTRACT}

BACKGROUND: The international literature on physicians, knowledge regarding radiation dosages and risks due to computed tomography showed a widespread underestimation of diagnostic radiation doses. Hence, the objective of this work is to assess the awareness of pediatric residents and medical interns about pediatric $C T$ dose and possible risks.

METHODS: A cross-sectional study was conducted on May/2016 among year I to year III pediatric residents and 2015/2016 year medical interns attaching Pediatrics Department during the study period in Tikur Anbessa Specialized Referral and Teaching Hospital. Data was collected by distributing standardized structured questionnaires. Finally, after the data was checked for clarity and completeness, it was analyzed by using SPSS software.

RESULT: While the majority (76.3\%) of the residents and interns knew that children were more sensitive to radiation than adults, 93.7\% did not know that there is currently no annual dose limit set for medical exposure of patients. The majority of the respondents (81.3\%) know the risk of cancer from CT scan, but most (60\%) of the respondents did not know that many imaging facilities still use adult doses for pediatric patients. Furthermore, 18.8\% thought that magnetic resonance imaging involves ionizing radiation, and $8.9 \%$ of the physicians associated ultrasound examinations with ionizing radiation.

CONCLUSION : Within resident group, since the level of clinical experience did not affect the outcome, we recommend that formal education and training on awareness of radiation with special concern on pediatric population is mandatory especially for pediatric residents and pediatricians who are major caretakers of children.

KEYWORDS: Computed tomography, radiation exposure, awareness of radiation, pediatric $\mathrm{CT}$ dose, possible risks of radiation. 


\section{INTRODUCTION}

In 1972, Computed Tomography (CT), a technique that produces non-superimposed, crosssectional images of the body, was introduced into clinical practice (1). Its introduction revolutionized diagnostic radiology, as it experienced rapid technological developments (fast acquisition and reconstruction times, spiral acquisition mode, multislice capability). Its use has also, in the last decade, grown considerably. As a result, the numbers of examinations have increased. By its nature, CT involves larger radiation doses than the more common conventional X-ray imaging procedures. This relatively high dose modality, represents about 5 $10 \%$ of all X-ray examinations, but contributes between $41 \%$ and $75 \%$ of the collective dose from diagnostic radiology in some countries (2-4).

It is estimated that more than 62 million CT scans per year are currently obtained in the United States, including at least 4 million for children (2). Most importantly, the largest increases in CT use have been in the category of pediatric diagnosis and this trend can only be expected to continue as investigative medicine remains standard practice for the next few years $(5,6)$. Thus, CT continues to form a major contribution to the collective diagnostic dose of the population.

The risk of cancer induction through CT scans performed on children has received special attention. Children are supposed to be at a higher risk for developing cancer caused by ionizing radiation compared to adults due to mainly the increased radio sensitivity and a longer life span after exposure. Though individual risks are small, the increasing use of CT scans in children make this an important public health problem.

The risks of pediatric CT have been assessed in several studies. Israeli researchers estimated that 9.5 lifetime deaths were associated with one year of pediatric CT scanning (8). Brenner and coworkers (2) estimated the lifetime cancer mortality risk attributable to the radiation exposure from abdomen or head CT in a one year old child based on USA CT-practice is 1 in $1000(0.18 \%$ for an abdominal CT and $0.07 \%$ for a head CT) (2).
These figures were calculated on the assumption that children were being imaged using adult CT parameters; the risk would be lower if specific pediatric CT protocols were uniformly adopted.

The international literature on physicians' knowledge regarding radiation dosages and risks due to computed tomography showed a widespread underestimation of diagnostic radiation doses (7-9). More concern has recently been aired in recent studies that the knowledge of referring doctors about radiation doses incurred during diagnostic CT procedures is deficient (1017). Such information may be of particular relevance when the expansion of CT technology is considered. The advent of Multi Detector row CT (MDCT) has allowed for faster imaging and the use of more complex imaging protocols. In turn, this has led to a rise in the number of CT examinations performed per annum and consequently in the amount of radiation to which patients are exposed (18). These will increase cancer incidence for exposed than for unexposed people (19).

Despite the increasing pediatric CT scan, there are no studies done regarding awareness of pediatric $\mathrm{CT}$ radiation dose and possible risks in Ethiopia. Therefore, as part of a project to improve radiation protection practice from $\mathrm{CT}$, particularly in the pediatric age group, we set out to study pediatric residents' and medical interns' awareness of pediatric $\mathrm{CT}$ radiation dose and possible risks in a cross-sectional survey at our hospital. This was planned with the aim of assessing awareness of physicians about justified use of CT imaging in pediatrics, offering recommendations on alternative diagnostic methods and giving emphasis on physicians' education pertaining to radiation safety.

\section{MATERIAL AND METHODS}

Study design: A cross-sectional study was conducted by distributing a standardized questionnaire. Multiple-choice survey comprising 14 items was distributed to 85 residents and medical interns in the Pediatric Department at Tikur Anbessa Specialized Referral and Teaching Hospital in May 2016. The questionnaire was divided into three main sections. The first two questions were directed towards obtaining 
demographic information. The second section assessed basic knowledge on the fundamentals of ionizing radiation, including radiation risks and its protection. The third section assessed the participants' ability to estimate the radiation dose of common radiological procedures. For this purpose, the effective dose of a postero-anterior chest X-ray for a 5-year old child $(0.006 \mathrm{mSv})$ was considered to be 1 unit.

Source population: All year I to year III pediatric residents and medical interns in the Pediatric Department were included in the study. Those who are unwilling to participate were excluded.

Sampling technique: The convenience sampling method was used while subjects are selected because of their convenient accessibility.

Data analysis: The data was checked for clarity and completeness. Then, it was analyzed by using password protected database for statistical analysis using a commercially available software SPSS version 21. In order to respect the study group's bill of right, ethical considerations were taken into account. Clear and detailed explanations were given to the study population about the objective of the study. Information was kept confidential by not recording names of respondents.

Ethical considerations: The study was conducted after approval by the Research and Ethics Committee of the department, who is autonomous to give ethical clearance for research proposal below $\mathrm{PhD}$ levels.

\section{RESULTS}

In order to assess general radiation knowledge of the study participants, 85 copies of the questionnaire were distributed. Among the 85 copies distributed, 80 were filled and collected. A total of 80 copies of the questionnaire were returned giving a response rate of $94 \%$. Some answers were missed for distribution of the effective dose estimations in percentage.

The responding group comprised 47 pediatric residents and 33 medical interns. Among the resdents who responded, 15 were in their senior year (year III), 12 in year II and the remaining 20 were in year I residency. (Table1).

Starting with the percentage of background radiation for which medical radiation is responsible, $17.5 \%$ of the answers were correct, $20 \%$ of the respondents underestimated the answer, 3.8\% overestimated the answer, and $58.8 \%$ responded 'Do not know' (Table 1). When asked about the annual dose a patient is allowed to receive when compared with radiation worker $93.7 \%$ did not know that there is currently no annual dose limit set for patients (Table 1). While the majority $(76.3 \%)$ of the residents and interns knew that children were more sensitive than adults to the negative effects of radiation (correct answer is 10 times), $20.1 \%$ underestimated the degree of sensitivity while $3.8 \%$ do not know (Table 1). Most $(60 \%)$ of the respondents did not know that many imaging facilities still use adult doses or do not make adequate adjustments for pediatric patients.

Regarding the risk of cancer from CT scan, the majority of the respondents $(81.3 \%)$ knew when asked about excess lifetime cancer risk for a 1 -year-old child undergoing any CT exam (correct answer, 1/1000) (7), 63\% answered 'Do not know'. Of the respondents who attempted to answer, $17 \%$ underestimated the risk while $20 \%$ of the doctors gave the correct answer (Table 1).

DOI: http://dx.doi.org/10.4314/ejhs.v28i4.4 
July 2018

Table 1: Assessment of general radiation knowledge

\begin{tabular}{|c|c|c|c|c|c|}
\hline \multirow{2}{*}{ General Radiation Knowledg } & \multicolumn{5}{|c|}{ Resident } \\
\hline & Intern $=33$ & Year $\mathrm{I}=20$ & Year I I $=12$ & Year III $=15$ & Total $=80$ \\
\hline What percent of ionizing radiation is Contributed by Medical Radiation? & $\#(\%)$ & $\#(\%)$ & $\#(\%)$ & $\#(\%)$ & $\#(\%)$ \\
\hline $1.50 \%$ & $2(6.1)$ & $2(10.0)$ & $0(0.0)$ & $0(0.0)$ & $4(5.0)$ \\
\hline $5 \%$ & $4(12.1)$ & $3(15.0)$ & $0(0.0)$ & $0(0.0)$ & $8(10.0)$ \\
\hline $15 \%$ & $2(6.1)$ & $1(5.0)$ & $1(8.3)$ & $1(6.7)$ & $4(5.0)$ \\
\hline $50 \%$ & $0(0)$ & $2(10.0)$ & $4(33.3)$ & $8(53.3)$ & $14(17.5)$ \\
\hline $90 \%$ & $0(0)$ & $0(0.0)$ & $1(8.3)$ & $2(13.3)$ & $3(3.8)$ \\
\hline I Don't Know & $25(75.8)$ & $12(60.0)$ & $6(50.30)$ & $4(26.7)$ & $47(58.8)$ \\
\hline Compared to Radiation worker, What is the annual dose of Patients? & $\#(\%)$ & $\#(\%)$ & $\#(\%)$ & $\#(\%)$ & $\#(\%)$ \\
\hline The same & $5(15.2)$ & $3(15.0)$ & $2(16.7)$ & $1(6.7)$ & $11(13.8)$ \\
\hline More than & $11(33.3)$ & $7(35.0)$ & $5(41.7)$ & $11(73.3)$ & $34(42.5)$ \\
\hline Less than & $14(42.4)$ & $9(45.0)$ & $3(25.0)$ & $1(6.7)$ & $27(33.8)$ \\
\hline Unlimited & $2(6.1)$ & $0(0.0)$ & $2(16.7)$ & $1(6.7)$ & $5(6.3)$ \\
\hline I don't Know & $1(3.0)$ & $1(5.0)$ & $0(0.0)$ & $1(6.7)$ & $3(3.8)$ \\
\hline How does the radio sensitivity of a child compared to an adult? & $\#(\%)$ & $\#(\%)$ & $\#(\%)$ & $\#(\%)$ & $\#(\%)$ \\
\hline The same & $6(18.2)$ & $2(10.0)$ & $1(8.3)$ & $0(0.0)$ & $9(11.3)$ \\
\hline Less radiosensitive & $5(15.2)$ & $1(5.0)$ & $0(0.0)$ & $1(6.7)$ & $7(8.8)$ \\
\hline More radiosensitive & $22(66.7)$ & $15(75.0)$ & $11(91.7)$ & $13(86.7)$ & $61(76.3)$ \\
\hline I don't know & $0(0.0)$ & $2(10.0)$ & $0(0.0)$ & $1(6.7)$ & $3(3.8)$ \\
\hline \multicolumn{6}{|c|}{ Do we have to altered technical parameters to reduce the dose while imaging pediatric patients with } \\
\hline CT? & $\#(\%)$ & $\#(\%)$ & $\#(\%)$ & $\#(\%)$ & $\#(\%)$ \\
\hline Yes & $18(54.5)$ & $6(30.0)$ & $4(33.3)$ & $4(26.7)$ & $32(40.0)$ \\
\hline No & $15(45.5)$ & $14(70.0)$ & $8(66.7)$ & $11(73.3)$ & $48(60.0)$ \\
\hline Do you think is there risk of developing cancer from CT scan & $\#(\%)$ & $\#(\%)$ & $\#(\%)$ & $\#(\%)$ & $\#(\%)$ \\
\hline Yes & $22(66.7)$ & $18(90.0)$ & $10(83.3)$ & $15(100.0)$ & $65(81.3)$ \\
\hline No & $11(33.3)$ & $2(10.0)$ & $2(16.7)$ & $0(0.0)$ & $15(18.8)$ \\
\hline \multicolumn{6}{|c|}{ If yes for the above question, What is the approximate estimated risk of cancer for a 1 year old child } \\
\hline No Excess Risk & $0(0.0)$ & $0(0.0)$ & $0(0.0)$ & $0(0.0)$ & $0(0.0)$ \\
\hline $1 / 1,000,000$ & $2(9.1)$ & $1(5.6)$ & $1(10.0)$ & $0(0.0)$ & $4(6.2)$ \\
\hline $1 / 100,000$ & $1(4.5)$ & $1(5.6)$ & $0(0.0)$ & $0(0.0)$ & $2(3.1)$ \\
\hline $1 / 10,000$ & $1(4.5)$ & $1(5.6)$ & $1(10.0)$ & $2(13.3)$ & $5(7.7)$ \\
\hline $1 / 1,000$ & $1(4.5)$ & $3(16.7)$ & $3(30.0)$ & $6(40.0)$ & $13(20.0)$ \\
\hline $1 / 100$ & $0(0.0)$ & $0(0.0)$ & $0(0.0)$ & $0(0.0)$ & $0(0.0)$ \\
\hline
\end{tabular}

DOI: http://dx.doi.org/10.4314/ejhs.v28i4.4 
Table 2. Continued....

\begin{tabular}{|c|c|c|c|c|c|}
\hline Should we routinely discuss the radiation risks with the child's family prior to a CT exam? & $\#(\%)$ & $\#(\%)$ & $\#(\%)$ & $\#(\%)$ & $\#(\%)$ \\
\hline Yes & $25(75.8)$ & $16(80.0)$ & $11(91.7)$ & $15(100.0)$ & $67(83.8)$ \\
\hline No & $2(6.1)$ & $4(20.0)$ & $1(8.3)$ & $0(0.0)$ & $7(8.8)$ \\
\hline I am Not Sure & $6(18.2)$ & $0(0.0)$ & $0(0.0)$ & $0(0.0)$ & $6(7.5)$ \\
\hline A. The decision should be left to the doctor because of lack of education of the patients' families & $0(0.0)$ & $3(75.0)$ & $1(100.0)$ & $0(0.0)$ & $4(57.0)$ \\
\hline $\begin{array}{l}\text { B. I think CT does not cause a radiation dose that can pose a meaningful risk to the health of } \\
\text { patients }\end{array}$ & $0(0.0)$ & $1(25.0)$ & $0(0.0)$ & $0(0.0)$ & $1(14.3)$ \\
\hline D. This can cause excess anxiety in the patient's family and can result in cancellation & $1(50.0)$ & $0(0.0)$ & $0(0.0)$ & $0(0.0)$ & $1(14.3)$ \\
\hline What do you think about dose of one brain or abdominal CT when compared with that of one CXR & $\#(\%)$ & $\#(\%)$ & $\#(\%)$ & $\#(\%)$ & $\#(\%)$ \\
\hline Equal & $0(0.0)$ & $1(5.0)$ & $0(0.0)$ & $0(0.0)$ & $1(1.3)$ \\
\hline More than & $31(93.9)$ & $17(85.0)$ & $10(83.3)$ & $15(100.0)$ & $73(91.3)$ \\
\hline Less than & $1(3.0)$ & $0(0.0)$ & $0(0.0)$ & $0(0.0)$ & $1(1.3)$ \\
\hline I don't know & $1(3.3)$ & $2(10.0)$ & $2(16.7)$ & $0(0.0)$ & $5(6.3)$ \\
\hline Have you ever received any specific education on radiation in medical imaging? & $\#(\%)$ & $\#(\%)$ & $\#(\%)$ & $\#(\%)$ & $\#(\%)$ \\
\hline No & $11(33.3)$ & $18(90.00$ & $10(83.3)$ & $15(100.0)$ & $54(67.5)$ \\
\hline
\end{tabular}


On the question whether the risk of ionization should be discussed with patients' families, $83 \%$ responded yes.7.5\% were not sure and $8.8 \%$ responded no for reasons given the next question. Four possible ideas were given for the no response for the respondents to choose. $57 \%$ responded that the doctor should make the decision since [atients' families lack knowledge on radiation hazards. $14.3 \%$ responded that if informed, patients' families might get anxious and cancel the radiological (CT) procedure. 14.3\% said there was no meaningful risk while the remaining $14.3 \%$ showed concern about lack of education and the possibility of creating anxiety in patients' families.

The last two questions of this section were about education. Nearly, $32.5 \%$ of the respondents recalled being educated on radiation exposure in medical imaging, of these, $96.2 \%$ took formal education most of these $(88 \%)$ were medical interns. A small percentage (3.8\%) of respondents had received informal education through personal reading, unofficial discussions with their colleagues, or the news media.
In order to assess the relative radiation doses, participants were asked to compare dose of abdominal or brain CT with CXR. A total of $91.3 \%$ answered correctly while $2.6 \%$ underestimates, and $6.3 \%$ of the participants did not know the answers.

The second question assessed the dose equivalents of different imaging procedures in comparison to a conventional X-ray radiograph in an adult (If the effective dose of an X-ray chest examination in an adult is being defined as reference, how much higher or lower is the dose from other imaging procedures) .The dose of a newborn due to an X-ray image was overestimated by $46.3 \%$ of the responders (Table 2). On the other hand, the radiation dose due to $\mathrm{CT}$ scan was underestimated both in adults $(26.3 \%)$ and children $(41.3 \%)$, and $21.3 \%$ of the participants had no idea about pediatric as well as adult CT dose compared with CXR. Furthermore, 18.8\% thought that magnetic resonance tomography involves ionizing radiation, and $8.9 \%$ of the physicians associated ultrasound examinations with ionizing radiation.

Table 2: Distribution of the effective dose estimations in percentage

\begin{tabular}{lccccccc}
\hline Projection & $\begin{array}{c}0<1 \\
\text { lower }\end{array}$ & $\begin{array}{c}1 \\
\text { reference }\end{array}$ & $\begin{array}{c}2-10 \\
\text { times } \\
\text { higher }\end{array}$ & $\begin{array}{c}11-100 \\
\text { times } \\
\text { higher }\end{array}$ & $\begin{array}{c}101-1000 \\
\text { times } \\
\text { higher }\end{array}$ & $\begin{array}{c}>1000 \\
\text { times }\end{array}$ & Missing \\
\hline Chest X-ray, Adult & 11.3 & $\mathbf{X}$ & & & & & \\
Chest X-ray, newborn & $\%$ & $12.50 \%$ & $46.30 \%$ & $26.30 \%$ & $0.00 \%$ & $2.50 \%$ & $1.10 \%$ \\
Chest CT, Adult & $2.5 \%$ & $7.50 \%$ & $16.30 \%$ & $25 \%$ & $15 \%$ & $2.50 \%$ & $31.20 \%$ \\
Chest CT children & & & & & & & \\
(without dose adjustment) & $2.5 \%$ & $7.50 \%$ & $20 \%$ & $11.30 \%$ & $33.80 \%$ & $3.80 \%$ & $21.10 \%$ \\
Abdomen CT, Children & $2.5 \%$ & $7.50 \%$ & $20 \%$ & $11.30 \%$ & $33.80 \%$ & $3.80 \%$ & $21.10 \%$ \\
Abdomen MRI, Children & $60 \%$ & $2.50 \%$ & $2.50 \%$ & $3.80 \%$ & $5 \%$ & $5 \%$ & $21.20 \%$ \\
Abdomen US, Children & $70 \%$ & $3.80 \%$ & $2.50 \%$ & $0 \%$ & $1.30 \%$ & $1.30 \%$ & $21.10 \%$ \\
\hline
\end{tabular}

DOI: http://dx.doi.org/10.4314/ejhs.v28i4.4 


\section{DISCUSSION}

Pediatric CT examinations are extremely important and are required for the diagnosis and treatment of many diseases in children. Despite its high importance, it exposes children for high burden of radiation if it is used unwisely. Children are the most vulnerable population to the deleterious effects of radiation. Though individual risks are small, the increasing use of CT scans in children make this an important public health problem. Despite the increased use of pediatric $\mathrm{CT}$ and the increasing number of papers and campaigns regarding pediatric radiation issues, there has not been an equal increase in the awareness of physicians. Various studies had documented deficiencies in knowledge among medical students, doctors and paramedics about their understanding of pediatric CT dose or the use of equipment involved in the process (7). Our survey also shows that physicians' awareness of the radiation doses imparted during pediatric CT scanning and the consequent risks to the individual patient is deficient. The level of understanding of the basic concepts behind radiological examinations and the knowledge of radiation risks and protection were poor. The majority of the participants $(78.8 \%)$ either did not know or underestimated the contribution of medical radiation to the total radiation exposure of patients. In one large survey done in Turkey in $2012,83.5 \%$ of the respondents either did not know or underestimated the contribution which is more than ours $(78.8 \%)$. The majority $(76.3 \%)$ of the residents and interns knew that children were more sensitive to radiation than adults; $93.7 \%$ did not know that there is currently no annual dose limit set for medical exposure of patients. In order not to restrict the benefits of X-rays which are generally higher than radiation risk, no international organization has provided a limit for patient dose. The risk associated with radiation is considered to be acceptable for medically justified examinations. The pediatricians are responsible for ensuring that the health benefit to the patient from the examination is greater than the radiation risks.
Regarding radio sensitivity of children and excess lifetime cancer risk, the result indicated that threefourth $(76.3 \%)$ of the respondents know that children are more radiosensitive than adults, and $20.1 \%$ underestimated the degree of sensitivity. The majority of the respondents $(63 \%)$ do not know about the excess lifetime cancer risk for a 1year-old child undergoing any CT exam, 20\% answered correctly, and $17 \%$ underestimated it. In one large survey done in Turkey in 2012, the majority $(76.3 \%)$ of the pediatricians knew that children were more sensitive than adults to the negative effects of radiation which is comparable with our result while $43 \%$ underestimated the degree of sensitivity which is better than ours (11). In the same survey, regarding lifetime cancer risk from pediatric CT, $44.7 \%$ had no awareness which is better than our result, the majority (64.2\%) underestimated the risk which is more than ours, and $11.8 \%$ answered that there was no increased risk. Only $18.1 \%$ of the doctors gave the correct answer, almost comparable with our result (4). The survey from Germany in 2012 regarding pediatric CT scan usage and awareness, only 3\% answered correctly about excess lifetime cancer risk for a 1-year-old child from CT which is less than our result and $13 \%$ did not respond to this question which is still better than our result (10).

From this, we can see that there is still a big knowledge gap among our physicians, and they are exposing their patients to more risk than they expect, even though $83.8 \%$ of the respondents believed that the risks should be routinely discussed with the child's family when a pediatric CT exam is requested. For the small group of residents and interns $(8.8 \%)$ who believed that the risks should not be discussed under any circumstances, the main concerns were the under education of the families and the possible stimulation of parental anxiety. From this point, we conclude that a discussion including the words 'cancer' and 'death' might be challenging and cause anxiety regardless of the level of education.

There is a risk that a much needed exam might be canceled by an overly anxious family if the necessity of the exams versus the risks is not properly communicated. Therefore, before 
providing information, the physicians themselves need to be accurately educated on the issue.

The majority of the residents and interns $(60 \%)$ did not know about the fact that many imaging facilities still use adult doses or do not make adequate adjustments for pediatric patients which is also comparable with the result from the survey done in Turkey in 2012 (60.3\%). This misinformation might result in physicians' requesting more than the necessary number of pediatric CT examinations and exposing their patients to more radiation risk.

There are no restrictions to the use of X-rays in children, provided that the clinical benefits exceed the small potential radiation risks. Some organs in children have higher radiation sensitivity than in adults. Children also have a longer life expectancy. Therefore, imaging techniques that do not use ionizing radiation should always be considered as an alternative. Children's radiological procedures should be individually planned and limited to what is sufficient for a correct diagnosis.

While making dose estimations, $8.7 \%$ of the respondents marked US and $18.7 \%$ marked MRI as techniques involving ionizing radiation. A survey from Ethiopia in 2012 revealed that 5.3\% and $7.1 \%$ of physicians thought that abdominal US and MR involved radiation, respectively (7). About $21.3 \%$ think that MRI has more radiation than X-rays (Table-2). These will lead them to order more X-ray examination for pediatric patients, which intern leads to unnecessary radiation. Although the risk with single X-ray study is mostly very small, it is a question of minimization of risk. Imaging examinations utilizing non-ionizing radiation such as MRI or ultrasound (US) should always be considered for appropriateness. Unlike X-rays, they are not known to increase the risk for cancer. In a similar survey from Germany, $12.9 \%$ thought that magnetic resonance imaging involves ionizing radiation, and $3.1 \%$ of the physicians associated ultrasound examinations with ionizing radiation (10). The awareness about ultrasound and MRI in our survey was less than that of the above surveys. This difference is likely to be due to the characteristics of the study group, which included only limited groups (pediatric residents and medical interns).

Regarding effective dose estimations and comparisons of groups, pediatric residents had a better understanding of children's radiation sensitivity than medical interns. Residents were also better than medical interns at estimating radiation doses though there is no significant difference between senior and junior residents at estimating radiation doses. This survey found that pediatric residents and interns were not adequately aware of the pediatric CT dose as well as general radiation. Our survey result is almost comparable with many of the surveys done world-wide most of which are done few years back and almost all of them showing poor awareness of physicians about pediatric CT. From this, we conclude that there is still a significant knowledge gap among physicians even among pediatric residents who are major caretakers of children regarding pediatric $\mathrm{CT}$ and general radiation, its risks and essential protection methods at Tikur Anbessa Specialized Teaching Hospital.

The majority of the study group were residents who would soon practice pediatric in the country. The problem we observed will affect the community they will serve. Hence, we recommend that formal education and training on awareness of radiation with special concern on pediatric population is mandatory especially for pediatric residents and pediatricians who are major caretakers of children. It is also better to re-educate physicians about radiation relevant to medical imaging and their clinical role to provide accurate information to their patients. 


\section{REFERENCES}

1. Ogbole G: Radiation dose in pediatric computed tomography: Risks and Benefits: Annals of Ibadan Postgraduate Medicine, 2010:8(2): 1-5.

2. Brenner D, Elliston C, Hall E, Berdon W: Estimated risks of radiation induced fatal cancer from pediatric CT. Am J Roentgenol 2001;176(2):289-296.

3. Pages J, Buls N, Osteaux M. CT doses in children: a multicentre study. The British Journal of Radiology. 2003;76: 803-811.

4. Wiest P, Locken J, Heintz P, Mettler F Jr. CT scanning: a major source of radiation exposure. Semin Ultrasound CT MR 2002;23:402-410.

5. White K. Helical/spiral CT scanning: a pediatric radiology perspective. PediatrRadiol 1996; 26:5-14.

6. Linton O, Mettler FA Jr. National conference on dose reduction in $\mathrm{CT}$, with an emphasis on pediatric patients. AJR Am J Roentgenol 2003; 181:321-329.

7. Zewdneh D, Teferi S, Ayele T, A study of Knowledge and Awareness of medical Doctors towards Radiation Risk at Tikur Anbessa Specialized Hospital, Addis Ababa, Ethiopia. IOSR Journal of Pharmacy and Biological Sciences (IOSRJPBS), 2012; 2(4): 01-05.

8. Chodick G, Ronckers CM, Shalev V, Ron E. Excess lifetime cancer mortality risk attributable to radiation exposure from computed tomography examinations in children. Isr Med Assoc J, 2007; 9: 584-587.

9. Louise P. New Study Shows Global Variation in Dose Levels for Child CT Scans, IAEA Division of Public Information. http://www.european-hospital.com/en/ar ticle/7145.html. accessed on 29 July 2015.
10. Hiltrud Merzenich, Lucian Krille, Gael Hammer, Melanie Kaiser, Shunichi Yamashita and Hajo Zeeb: Pediatric CT scan usage and referrals of children to computed tomography in Germany: A cross-sectional survey of medical practice and awareness of radiation related health risks among physicians. $B M C$ Health Services Research, 2012: 12: 47.

11. Ayşe S, ÇiğdemÜ..Pediatricians' awareness of diagnostic medical radiation effects and doses: are the latest efforts paying off?. Turkish Society of Radiology 2012; 18 (1): 78-82.

12. Lee CI, Haims AH, Monico EP, Brink JA, Forman HP. Diagnostic CT scans: assessment of patient, physician, and radiologist awareness of radiation dose and possible risks. Radiology, 2004; 231: 393-398.

13. Smith-Bindman R, Miglioretti DL, Larson EB. Rising use of diagnostic medical imaging in a large integrated health system. Health Aff(Millwood) 2008; 27: 1491-15.

14. Shiralkar S, Rennie A, Snow M, Galland RB, Lewis MH, Gower-Thomas K. Doctors' knowledge of radiation exposure: questionnaire study. $B M J 2003 ; 327: 371-372$ DOI: 10.11 36/bmj.327.7411 .371].

15. Soye J, Paterson A. A survey of awareness of radiation dose among health professionals in Northern Ireland. Br J Radiol2008; 81: 725729. DOI: $10.1259 / \mathrm{bjr} / 94101717]$.

16. Moss M, McLean D. Paediatric and adult computed tomography practice and patient dose in Australia. AustralasRadiol2006; 50: 33-40. DOI: $10.1111 /$ j.1440-1673.2005.015 44.x]

17. Jacob K, Vivian G, Steel JR. X-ray dose training: are we exposed to enough? ClinRadiol, 2004; 59: 928-934.

DOI: 10.1016/j.crad.2004.04.020].

18. Hussein Almohiy:.Pediatric computed tomography radiation dose: A review of 
the global dilemma. World Journal of Radiology (WJR), 2014 ; 6(1): 1-6.
19. Mathews JD, Forsythe AV, Brady Z, Butler MW, et al. Cancer risk in 680,000 people exposed to computed tomography scans in childhood or adolescence: data linkage study of 11 million Australians. BMJ, 2013;21:346. doi: 10.1136/bmj.f2360. 